\title{
DESENVOLVIMENTO DE FOLÍCULOS PRÉ-ANTRAIS BOVINOS IN VITRO EM MONOCAMADA DE CÉLULAS OVARIANAS ${ }^{1}$
}

\author{
IN VITRO DEVELOPMENT OF BOVINE PREANTRAL FOLLICLES IN MONOLAYER OF \\ OVARIAN CELLS ${ }^{1}$
}

\author{
Luís Fabiano Santos da Costa ${ }^{2}$ Paulo Bayard Dias Gonçalves ${ }^{3}$ José Ricardo Figueiredo $^{4}$ \\ Silvia Ferreira Carámbula ${ }^{2}$ Jairo Pereira Neves ${ }^{3}$ Marcelo Marcos Montagner ${ }^{2}$
}

RESUMO

O presente trabalho teve como objetivos determinar a influência de células ovarianas no desenvolvimento in vitro de folículos pré-antrais, avaliar a viabilidade das células ovarianas em monocamada e a influência do soro na manutenção de folículos pré-antrais in vitro. Folículos pré-antrais (FPs) e células ovarianas foram isolados de ovários de fetos bovinos, com idade entre 6 e 8 meses de gestação, oriundos de matadouro. Células ovarianas em monocamada foram cultivadas em meio TCM-199, e a viabilidade celular, após o cultivo na presença ou ausência de FSH, foi determinada com o corante vital azul de tripan. FPs foram distribuidos em quatro tratamentos e cultivados em TCM199 modificado, contendo soro de novilho castrado (SNC), SNC em monocamada de células ovarianas (MCO), MCO com FSH ou meio definido com álcool polivinílico (PVA) como macromolécula. A viabilidade celular não foi afetada em conseqüência da presença ou ausência de FSH. No entanto, houve um incremento significativo no tamanho dos FPs cultivados na presença de SNC, MCO e FSH $(P<0,05)$, o que não foi observado nos demais tratamentos. A adição de FSH ao meio de cultivo não influencia a viabilidade de células ovarianas ao longo de 20 dias. Folículos pré-antrais, com área superficial entre 4000 e $8000 \mu^{2}$, mas não folículos com área superficial superiores a $8000 \mu \mathrm{m}^{2}$, crescem in vitro na presença de células ovarianas, independentemente da presença de FSH.

Palavras-chave: folículos pré-antrais, bovinos, células ovarianas.

\section{SUMMARY}

The aim of the present work was to determine the influence of ovarian cells in the in vitro development of preantral follicles $(P F)$. The viability of monolayer ovarian cells and the effect of the serum in the survive of in vitro $P F$ was also investigated. Ovarian cells and PF were isolated from ovaries of bovine fetus between 6 and 8 months of pregnancy, obtained in a slaughterhouse. Monolayer of ovarian cells were cultured in a modified TCM-199 in the presence and absence of FSH and its viability after incubation was determined with Trypan Blue. PFs were divided in four different treatments, cultured in modified TCM-199, containing serum of castrated steer (SCS), SCS in monolayer of ovarian cells (MOC), MOC with FSH or a defined medium with polyvinyl alcohol (PVA) as macromolecule. The cellular viability was not affected by the presence or absence of FSH. However, PFs had a significant development $(P<0.05)$ when cultivated in the presence of SNC, MCO and FSH, which was not observed in the other treatments. With these results, it was possible to conclude that FSH does not influence the viability of the ovarian cells when cultured in a monolayer for 20 days. Preantral follicles, measuring between 4000 and $8000 \mu^{2}$ but not with size greater than $8000 \mu^{2}$, grow on ovarian cells in vitro, independently of FSH.

Key words: preantral follicles, bovine, ovarian cells.

\section{INTRODUÇÃO}

O isolamento e crescimento de folículos pré-antrais (FPs) têm se mostrado como uma das biotecnologias de maior potencial na área de reprodução animal. O número de folículos que uma fêmea irá dispor já está determinado antes do nascimento (FRANCHI et al., 1962). Aos 110 dias de gestação, o número médio de folículos nos ovários de um feto bovino é de, aproximadamente, 2.700.000, decrescendo até o nascimento para cerca de 130.000 folí-

\footnotetext{
${ }^{1}$ Trabalho realizado com apoio financeiro da FAPERGS e CNPq.

${ }^{2}$ Médico Veterinário, Mestre.

${ }^{3}$ Professor Titular, Doutor, Departamento de Clínica de Grandes Animais, Centro de Ciências Rurais, Universidade Federal de Santa Maria, 97105-900 Santa Maria, RS. E-mail: bayard@lince.hcv.ufsm.br. Autor para correspondência.

${ }^{4}$ Professor, Doutor, Universidade Estadual do Ceará.
} 
culos pré-antrais (ERICKSON, 1966), através de processos degenerativos ou apoptóticos.

As técnicas de recuperação desse material já estão bem caracterizadas na espécie bovina (FIGUEIREDO $\boldsymbol{e} \boldsymbol{t} \boldsymbol{a l}$., 1993; CARÁMBULA $\boldsymbol{e} \boldsymbol{t} \boldsymbol{a l}$., 1998), obtendo-se um grande número de FPs. A obtenção de camundongos nascidos a partir de folículos pré-antrais desenvolvidos in vitro (EPPIG \& SHROEDER, 1989) estimulou a pesquisa em espécies de interesse comercial como suínos (TELFER, 1996) e bovinos (HULSHOF $\boldsymbol{e t}$ al., 1995; WANDJI et al., 1996). O sistema de cultivo celular em monocamada já havia sido descrito, utilizando gel de colágeno (TORRANCE et al., 1989; EPPIG, 1992) e ágar gel (ROY \& GREENWALD, 1989; HIRAO et al., 1990; EPPIG, 1992; WANDJI et al., 1996). O co-cultivo de células ovarianas viáveis com FPs pode ter um efeito positivo sobre o desenvolvimento, pois a ausência dessas células no meio de cultivo está associada à alta taxa de atresia observada in vitro (CARROLL et al., 1990).

O FSH foi amplamente utilizado no cultivo de FPs in vitro (HULSHOF et al., 1995; EPPIG \& O'BRIEN, 1996; WANDJI et al., 1996), mas não há relatos da sua influência sobre FPs quando cultivados sobre uma monocamada de células ovarianas. Assim sendo, o presente trabalho teve como objetivos determinar a viabilidade das células ovarianas em monocamada e a influência da associação de células ovarianas, soro e FSH na manutenção e no desenvolvimento in vitro de folículos pré-antrais bovinos.

\section{MATERIAL E MÉTODOS}

Ovários de fetos bovinos em idades de gestação entre 6 e 8 meses, avaliados através do comprimento crânio-caudal segundo RÜSSE (1983), foram coletados em matadouro logo após o abate dos animais. Os ovários foram transportados até o laboratório em recipientes isotérmicos com temperatura em torno de $30^{\circ} \mathrm{C}$ em meio TCM-199. No laboratório, os ovários foram lavados três vezes em meio TCM-199 e os tecidos adjacentes foram removidos. Os ovários, após estarem livres de qualquer outro tecido, foram colocados em um tubo plástico de centrífuga com capacidade de $12 \mathrm{~m} \ell$, contendo TCM-199 com sais de Earle e glutamina, acrescido de $25 \mathrm{mM}$ de Hepes, $100 \mathrm{UI} / \mathrm{m} \ell$ de penicilina, $50 \mu \mathrm{g} / \mathrm{m} \ell$ de estreptomicina e $1,0 \mathrm{mg} / \mathrm{m} \ell$ de PVA. Em seguida, os ovários foram submetidos a um processo de dissociação, utilizando o método mecânico para isolamento de FPs, desenvolvido por FIGUEIREDO et al. (1993) e adaptado por CARÁMBULA $\boldsymbol{e t}$ al. (1998).
Células ovarianas, obtidas por esse processo, foram divididas em dois grupos, com (Grupo FSH) e sem (Grupo controle) FSH, cultivadas em meio TCM-199 modificado acrescido de $10 \%$ de soro de novilho castrado (SNC) em gotas

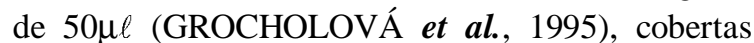
com óleo silicone e incubadas em estufa contendo uma atmosfera de $5 \%$ de $\mathrm{CO}_{2}$ em ar, umidade saturada e temperatura de $39^{\circ} \mathrm{C}$. O FSH foi adicionado na concentração de $1,0 \mu \mathrm{g} / \mathrm{m} \ell$ de meio. $\mathrm{O}$ número de células foi ajustado a uma concentração final de $2 \times 10^{4}$ células $/ \mathrm{ml}$ de meio de cultivo, contadas através de uma câmara de Neubauer (GROCHOLOVÁ et al., 1995). As placas, contendo uma monocamada confluente de células, foram submetidas à coloração vital pelo método descrito por KRAUSE et al. (1984), utilizando Azul de Tripan como corante vital. As células foram coradas nos dias $2,5,8,11,14,17$ e 20 de cultivo, sendo que células de cada ovário foram semeadas em sete placas, respectivamente para cada dia de análise. A contagem e avaliação quanto à reatividade ao corante vital foram determinadas por visualização sob microscópio invertido.

Para avaliar o percentual de recuperação de FPs bovinos após cultivo in vitro, utilizando monocamada de células ovarianas, 206 folículos de tamanhos entre 40 e $70 \mu \mathrm{m}$ foram cultivados individualmente em gotas de $50 \mu \ell$, em uma atmosfera de $5 \%$ de $\mathrm{CO}_{2}$ em ar, umidade saturada e temperatura de $39^{\circ} \mathrm{C}$. Os FPs foram alocados aleatoriamente em quatro grupos, tendo como meio básico para cultivo o TCM-199 com sais de Earle e glutamina, acrescido de $25 \mathrm{mM}$ de Hepes, $100 \mathrm{UI} / \mathrm{m} \ell$ de penicilina, $50 \mu \mathrm{g} / \mathrm{m} \ell$ de estreptomicina, $0,2 \mathrm{mM}$ de piruvato de sódio, $2,2 \mathrm{mg} / \mathrm{m} \ell$ de bicarbonato de sódio. Para o cultivo, foram adicionados ao meio básico $10 \%$ de SNC (grupo SOR), 10\% de SNC e células ovarianas (grupo SOM), 10\% de SNC, células ovarianas e $1,0 \mu \mathrm{g}$ de $\mathrm{FSH} / \mathrm{m} \ell$ de meio (grupo SOMF) e $1,0 \mathrm{mg}$ de PVA/m $\ell$ de meio (grupo PVA).

Para determinar o crescimento folicular, folículos pré-antrais com área superficial entre 4000 e $8000 \mu \mathrm{m}^{2}(\mathrm{n}=81)$ e entre 8001 e $15000 \mu \mathrm{m}^{2}(\mathrm{n}=73)$ foram distribuídos e cultivados nos grupos SOR, SOM e SOMF. A avaliação e tomada das medidas dos folículos foram realizadas nos dias $0,1,4,7$ e 10 de cultivo, com auxílio de um microscópio invertido equipado com micrômetro. $\mathrm{O}$ cálculo para determinar a área superficial (AS) foi o mesmo utilizado por van WEZEL \& RODGERS (1996), fazendo uso da seguinte fórmula: $\mathrm{AS}=4 . \pi[(1 / 8) \mathrm{M} \cdot \mathrm{m} \cdot \mathrm{m}]^{2 / 3}$, sendo, AS é a área superficial, $\mathrm{M}$ o diâmetro maior do folículo e $\mathrm{m}$ o diâmetro menor. A terceira medida folicular, correspondente à profundidade ou altura do 
folículo, foi assumida como o mesmo valor de $\mathrm{m}$. Foram avaliadas a taxa de recuperação folicular, o percentual de desenvolvimento e o incremento médio na área superficial de FPs nos diferentes grupos e dias.

Para a análise estatística da viabilidade celular, inicialmente os dados foram submetidos a uma análise de heterogeneidade das curvas e, posteriormente, foi realizada a análise de covariância, tendo em vista que as curvas eram homogêneas. Para a avaliação do percentual de recuperação (folículos que se mantiveram no meio) e desenvolvimento folicular (folículos que apresentaram crescimento no meio de cultivo), foi utilizado o teste de ANOVA, incluindo no modelo os diferentes dias em que os tratamentos foram PROC RANK, no SAS. O incremento na área superficial nos diferentes dias de cultivo foi analisado por regressão polinomial.

\section{RESULTADOS E DISCUSSÃO}

A verificação da viabilidade da monocamada em cultivo foi necessária para quantificar o tempo disponível para uso das células como sistema de cultivo. Em relação aos índices de viabilidade celular, nos diferentes dias de cultivo, não foi observado efeito em consequiência da adição ou não de FSH no meio de cultivo celular (Figura 1). Assim sendo, foi demonstrado que as células ovarianas permanecem viáveis por um período de até 20 dias, o que significa que as mesmas podem interagir com FPs, quando cultivados in vitro, uma vez que a ausência dessas células no cultivo pode determinar uma maior taxa de atresia folicular (CARROLL $\boldsymbol{e t}$ al., 1990).

A percentagem de folículos recuperados nos diferentes grupos, ao primeiro dia de cultivo, não diferiu significativamente ( $\mathrm{P}>0,05$; Figura 2$)$.

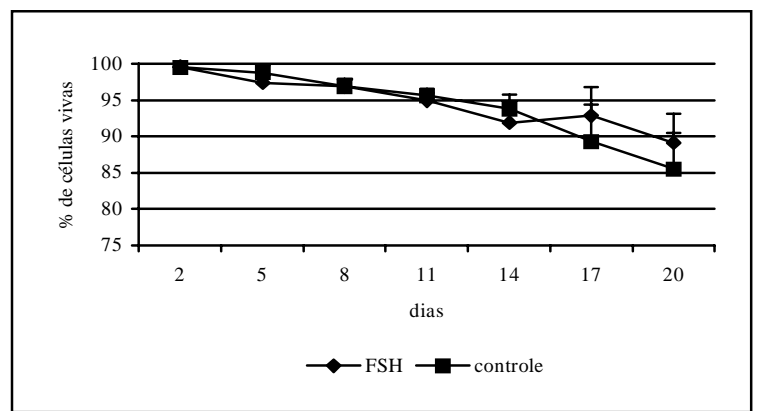

Figura 1 - Percentual de células viáveis em diferentes dias de avaliação. Não houve diferença na viabilidade das células ovarianas cultivadas com ou sem adição de $1,0 \mu \mathrm{g}$ de $\mathrm{FSH}$ por $\mathrm{m} \ell$ de meio. Os grupos foram cultivados simultaneamente

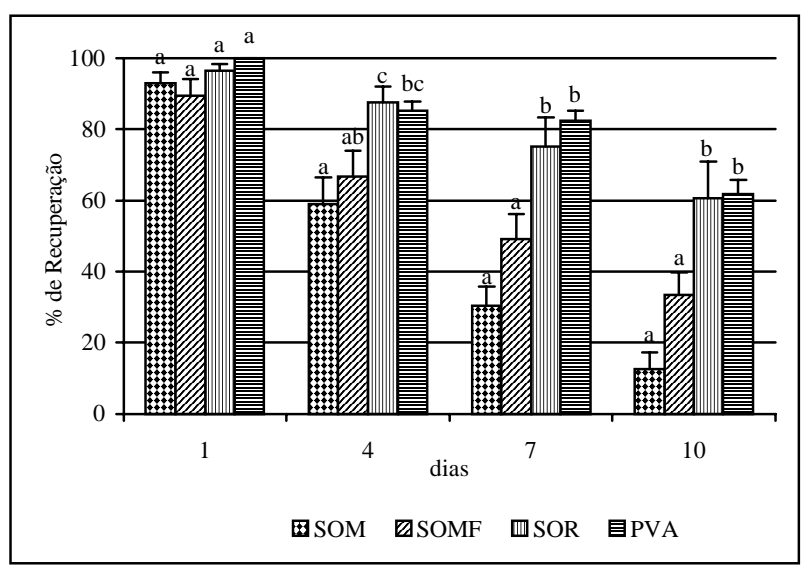

Figura 2 - Recuperação de folículos pré-antrais cultivados isoladamente em $50 \mu \ell$ de meio. Os folículos pré-antrais foram cultivados em TCM-199 acrescido de 10\% de soro de novilho castrado (SNC) e células ovarianas (grupo SOM), TCM-199 acrescido de 10\% de SNC, células ovarianas e $1,0 \mu \mathrm{g} / \mathrm{m} \ell$ de meio de FSH (grupo SOMF), TCM-199 acrescido de $10 \%$ de SNC (grupo SOR) e TCM-199 acrescido de $1,0 \mathrm{mg} / \mathrm{m} \ell$ de meio de álcool polivinílico (PVA; grupo PVA). Os valores representam os percentuais médios de oito replicações; letras diferentes indicam diferença estatística $(\mathrm{P}<0,05)$.

No dia 4 de cultivo, a percentagem de recuperação folicular no grupo PVA foi superior ao grupo SOM $(\mathrm{P}=0,0245)$ e similar aos resultados obtidos nos grupos SOMF e SOR. Da mesma forma, a superioridade na recuperação folicular em cultivos sem monocamada se manifestou no grupo SOR, o qual apresentou índices de recuperação folicular mais elevados do que os grupos em que os folículos foram cultivados na presença de monocamada. Esse fato foi similar nos dias 7 e 10 de cultivo folicular, nos quais se obteve uma maior recuperação folicular nos grupos em que a monocamada de células ovarianas estava ausente no sistema de cultivo (Figura 2). A utilização da monocamada como um meio de suporte para a manutenção de folículos pré-antrais não apresentou efeito benéfico sobre o número de folículos recuperados ao final do cultivo. Em contrapartida, os folículos cultivados somente na presença de soro ou PVA tiveram um percentual de recuperação maior. Alguns sistemas de cultivo de FPs utilizam o tratamento das superfícies plásticas com ágar gel (ROY \& GREENWALD, 1989) ou uma solução de ágar a 1\% (HIRAO et al., 1990; CARROLL et al., 1990; EPPIG, 1992; WANDJI et al., 1996). O colágeno foi utilizado como um sistema tridimensional para cultivo de folículos pré-antrais de camundongo (TORRANCE et al., 1989; EPPIG, 1992) e bovinos (HULSHOF et al., 1995; FIGUEIREDO et al., 1995), proporcionando uma estrutura física semelhante ao ovário. Recentemente, EPPIG \& O'BRIEN (1996) desenvolveram um sistema baseado em uma 
monocamada de células do estroma ovariano de camundongo, para cultivo de FPs. Com esses sistemas de cultivo, segundo os autores, não há perdas durante as manipulações e a integridade folicular é mantida, porém um sistema de cultivo utilizando células ovarianas de fetos bovinos é descrito na literatura.

O percentual de folículos que apresentaram crescimento, no primeiro e no quarto dia de cultivo, não diferiu significativamente entre os grupos $(\mathrm{P}>0,05)$. No entanto, no sétimo e décimo dia, a percentagem de FPs desenvolvidos no grupo SOMF foi superior $(\mathrm{P}<0,05)$ ao grupo $\mathrm{SOM}$ e numericamente superior aos demais tratamentos (Figura 3). Também, pode ser observado que, no primeiro dia de cultivo, em torno de $58 \%$ dos folículos apresentaram desenvolvimento. Esse percentual decresceu ao longo do período de cultivo, permanecendo o percentual de desenvolvimento folicular em $15 \%$ ao final da avaliação. A percentagem de desenvolvimento foi similar nos grupos de FPs cultivados na presença ou ausência de soro, demonstrando a capacidade de sobrevivência desses folículos na ausência de soro.

Com relação ao crescimento folicular in vitro, folículos com tamanho entre 4000 e $8000 \mu \mathrm{m}^{2}$ se desenvolveram quando células ovarianas em monocamada (grupo SOM; $\mathrm{p}=0,0028$ ), ou

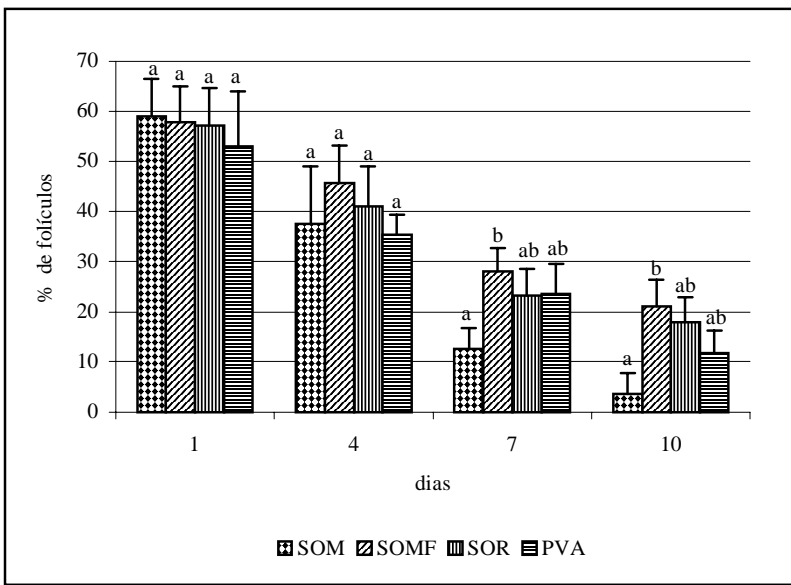

Figura 3 - Percentual de folículos pré-antrais que apresentaram desenvolvimento, avaliado pelo incremento na sua área superficial. Os folículos foram cultivados isoladamente em gotas de $50 \mu \ell$ de meio, por até 10 dias, em meio TCM-199 acrescido de $10 \%$ de soro de novilho castrado (SNC) e células ovarianas (grupo SOM), TCM-199 acrescido de 10\% de SNC, células ovarianas e $1,0 \mu \mathrm{g} / \mathrm{m} \ell$ de meio de $\mathrm{FSH}$ (grupo SOMF), TCM-199 acrescido de 10\% de SNC (grupo SOR) e TCM-199 acrescido de $1,0 \mathrm{mg} / \mathrm{m} \ell$ de meio de álcool polivinílico (PVA; grupo PVA). Os valores representam os percentuais médios de oito replicações; letras diferentes indicam diferença estatística $(\mathrm{p}<0,05)$. associadas ao FSH (grupo SOMF; p=0,001), estavam presentes (Figura 4a). Na ausência dessas células (grupo SOR), não houve crescimento folicular $(\mathrm{p}>0,05)$. No entanto, folículos com área superficial acima de $8000 \mu \mathrm{m}^{2}$ não foram capazes de crescer independentemente das condições de cultivo (SOM, SOMF e SOR; Figura 4b). Além disso, houve uma diminuição do tamanho dos folículos cultivados na presença de células ovarianas em monocamada (grupo SOM; $\mathrm{p}=0,048$ ), evidenciando a ocorrência de atresia folicular in vitro.

CARROLL et al. (1990) supõem que uma das causas da alta taxa de atresia folicular in vitro está associada à ausência de células ovarianas no cultivo folicular. Porém, ao ser observado, neste trabalho que folículos com área superficial entre 4000 e $8000 \mu \mathrm{m}^{2}$ se desenvolvem e folículos acima de $8000 \mu \mathrm{m}^{2}$ diminuem de tamanho, outros fatores devem ser considerados na atresia folicular in vitro. Primeiramente, esses resultados evidenciam que fatores parácrinos liberados pelas células ovarianas são fundamentais para o crescimento folicular até um determinado estádio de desenvolvimento. Acima de $8000 \mu \mathrm{m}^{2}$ de área superficial, são requeridos, para o desenvolvimento folicular, outros fatores que não estão presentes em um meio contendo soro, células ovarianas e FSH.

Tem sido proposto que FSH possui uma função essencial no crescimento de folículos préantrais in vitro (HULSHOF et al., 1995; EPPIG \& O'BRIEN, 1996; TELFER, 1996; WANDJI et al., (1996). No entanto, neste trabalho, ficou evidenciado que a presença de FSH não é fundamental para que folículos, com área superficial entre 4000 e $8000 \mu^{2}$, desenvolvam-se quando células ovarianas estão presentes. O mecanismo de ação pelo qual as células ovarianas em monocamada interagem com os folículos não ficou demonstrado, mas, provavelmente, essas células produzam fatores essenciais para o desenvolvimento folicular precoce, proporcionando um ambiente mais próximo ao que ocorre in vivo.

\section{CONCLUSÕES}

A adição de FSH ao meio de cultivo não influencia a viabilidade de células ovarianas ao longo de 20 dias. Folículos entre 4000 e $8000 \mu \mathrm{m}^{2}$ de área superficial crescem in vitro na presença de células ovarianas em monocamada, independentemente da presença de FSH. No entanto, células ovarianas e FSH, em meio contendo soro de novilho castrado, não proporcionam um ambiente favorável para o desenvolvimento de folículos com área superficial superiores a $8000 \mu \mathrm{m}^{2}$. 


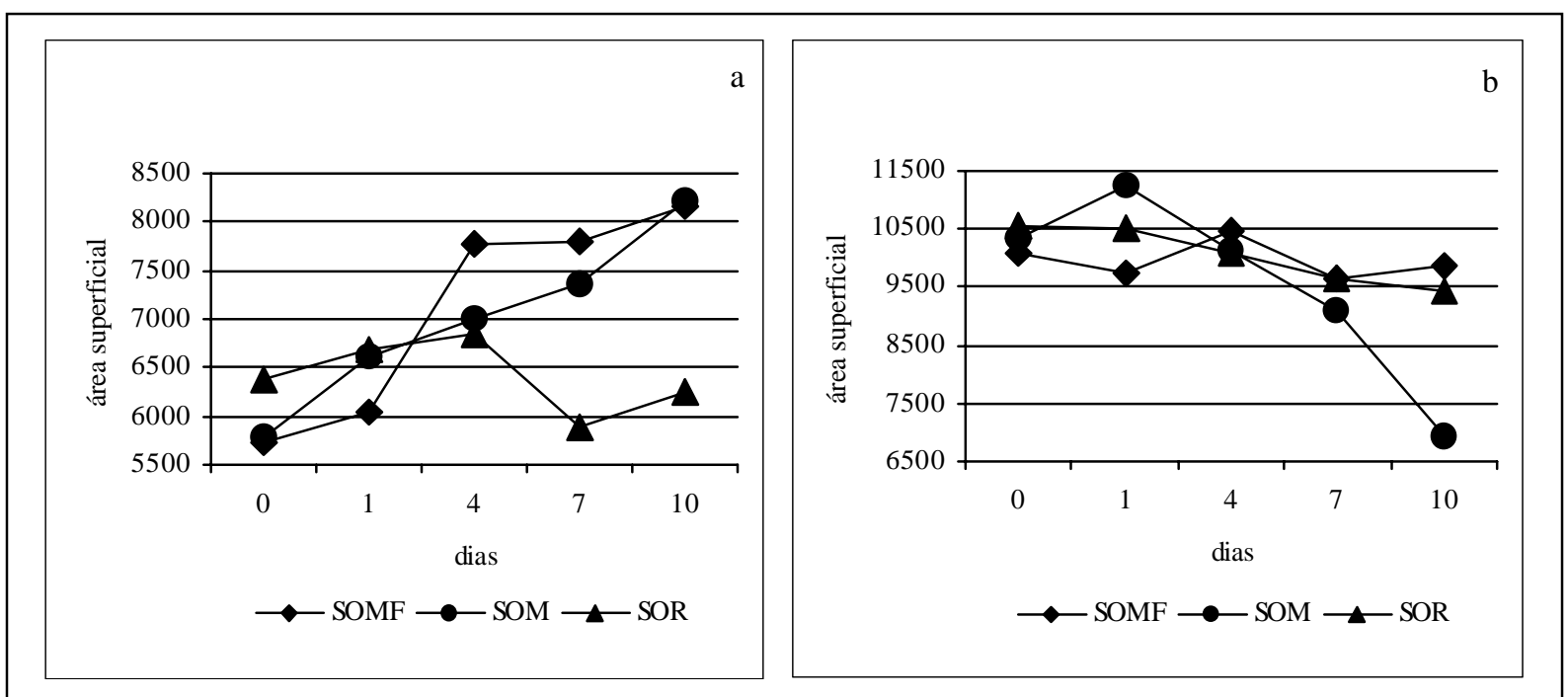

Figura 4 - Ação do soro de novilho castrado (SNC), células ovarianas em monocamada e FSH no crescimento de folículos pré-antrais. A área superficial de folículos pré-antrais, em $\mu \mathrm{m}^{2}$, foi avaliada em um período de 10 dias. Na figura "a", os folículos com área superficial entre 4000 e $8000 \mu \mathrm{m}^{2}$ foram cultivados em meio contendo 10\% SNC (grupo SOR), células ovarianas em monocamada e 10\% de SNC (grupo SOM) ou células ovarianas em monocamada, $10 \%$ de SNC e $1,0 \mu \mathrm{g} / \mathrm{m} \ell$ de FSH (grupo SOMF). Na figura "b", folículos com área superficial entre 8001 e $15000 \mu \mathrm{m}^{2}$ foram distribuídos e cultivados nos mesmos grupos. Os valores representam médias de folículos nos diferentes dias de cultivo.

\section{REFERÊNCIAS BIBLIOGRÁFICAS}

CARÁMBULA, S.F., GONÇALVES, P.B.D., COSTA, L.F.S. et al. Períodos de digestão enzimática para resgate de folículos pré-antrais em ovários de fetos bovinos. Ciência Rural, v.28, n.4, p.659-663, 1998.

CARROLL, J., WHITTINGHAN, D.G., WOOD, M.J. et al. Extra-ovarian production of mature viable mouse oocyte from frozen primary follicle. J Reprod Fert, v.90, p.321-327, 1990.

EPPIG, J.J. Growth and development of mammalian oocytes in vitro. Arch Pathol Lab Med, v.116, p.379-382, 1992.

EPPIG, J.J., SHROEDER, A.C. Capacity of mouse from preantral follicles to undergo embryogenesis and development to live young after growth, maturation and fertilization in vitro. Biol Reprod, v.41, p.268-276, 1989.

EPPIG, J.J., O'BRIEN, M.J. Development in vitro of mouse oocytes from primordial follicles. Biol Reprod, v.54, p.197207, 1996.

ERICKSON, B.H. Development and radio-response of the prenatal bovine ovary. J Reprod Fert, v.10, p.97-105, 1966.

FIGUEIREDO, J.R., HULSHOF, S.C.J., VAN DEN HURK, R. et al. Development of a combined new mechanical and enzymatic method for the isolation of intact preantral follicles from fetal, calf and adult bovine ovaries. Theriogenology, v.40, p.789-799, 1993.

FIGUEIREDO, J.R., HULSHOF, S.C.J., THIRY, M.R. et al. Extracellular matrix proteins and basement membrane: identification in bovine ovaries and significance for the attachment of cultured preantral follicles. Theriogenology, v.43, p.845-858, 1995.

FRANCHI, L.L., MANDL, M.A., ZUCKERMAN, S. The ovary. New York: Academic, 1962.
GROCHOLOVÁ, R., PETR, J., MAREK, J. et al. Beneficial influence of vero cells on in vitro maturation and fertilization of bovine oocytes. Theriogenology, v.44, p.199-207, 1995.

HIRAO, Y., MIYANO, T., KATO, S. Fertilization of in vitro growth mouse oocytes. Theriogenology, v.34, p.1071-1077, 1990.

HULSHOF, S.C., FIGUEIREDO, J.R., BECKERS, J.F. et al. Effects of fetal bovine serum, FSH and $17 \beta$-estradiol on the culture of bovine preantral follicles. Theriogenology, v.44, p.217-226, 1995.

KRAUSE, A.W., CARLEY, W.W., WEBB, W.W. Fluorescent erythrosin $\mathrm{B}$ is preferable to trypan blue as a vital exclusion dye for mammalian cells in monolayer culture. J Histoch Cytoch, v.32, p.1084-1090, 1984.

ROY, S.K., GREENWALD, G.S. Hormonal requirements for the growth and differentiaton of hamster preantral follicles in long-term culture. J Reprod Fert, v.87, p.103-114, 1989.

RÜSSE, I. Oogenesis in catlle and sheep. Bib Anat, v.24, p.7792,1983

TELFER, E.E. The development of methods for isolation and culture of preantral follicles from bovine and porcine ovaries. Theriogenology, v.45, p.101-110, 1996.

TORRANCE, C., TELFER, E., GOSDEN, R.G. Quantitative study of the development of isolated mouse pre-antral follicles in collagen gel culture. J Reprod Fert, v.87, p.367374, 1989.

van WEZEL I, RODGERS RJ. Morphological characterization of bovine primordial follicles and their environment in vivo. Biol Reprod, v.55, p.1003-1011, 1996.

WANDJ, S.A., EPPIG, J.J., FORTUNE, J.E. FSH and growth factors affect the growth and endocrinology function in vitro of granulosa cells of bovine preantral follicles. Theriogenology, v.45, p.817-832, 1996. 